\title{
The Role of Toll-Like Receptors and Myeloid Differentiation Factor 88 in Bjerkandera adusta- Induced Lung Inflammation
}

\author{
Miao He ${ }^{a}$ Takamichi Ichinose $^{b}$ Yuan Song ${ }^{c}$ Yasuhiro Yoshida $^{c}$ \\ Fumihisa Kobayashid $^{d}$ Teruya Maki $^{\mathrm{e}}$ Seiichi Yoshidab Hirohisa Takano ${ }^{\mathrm{f}}$ \\ Takayuki Shibamoto $^{g}$ Guifan Sun $^{a}$

\begin{abstract}
aEnvironment and Non-Communicable Disease Research Center, School of Public Health, China Medical University, Shenyang, China; ${ }^{\mathrm{b}}$ Department of Health Sciences, Oita University of Nursing and Health Sciences, Oita,

'Department of Immunology and Parasitology, School of Medicine, University of Occupational and Environmental Health, Fukuoka, d Faculty of Natural Systems, College of Science and Engineering, and ${ }^{\mathrm{e}}$ Faculty of Chemistry, Institute of Science and Engineering, Kanazawa University, Ishikawa, and fDivision of Environmental Health, Department of Environmental Engineering, Graduate School of Engineering, Kyoto University, Kyoto, Japan; ${ }^{9}$ Department of Environmental Toxicology, University of California, Davis, Davis, Calif., USA
\end{abstract}

\section{Key Words}

Bjerkandera adusta $\cdot$ Eosinophilia $\cdot$ Lung inflammation · Tolllike receptor $\cdot$ Innate immunity $\cdot$ Myeloid differentiation factor 88 - Macrophage

\footnotetext{
Abstract

Background: Recently, a cluster of patients with an intractable allergic fungal cough who were characterized by sensitization to Bjerkandera adusta was reported. In the present study, the role of Toll-like receptors and myeloid differentiation factor 88 (MyD88) in B. adusta-induced lung inflammation was investigated. Methods: Wild-type (WT), $T L R 2^{-/-}$, $T L R 4^{-/-}$, and $M y D 88^{-/-}$BALB/c mice were intratracheally challenged with $B$. adusta 4 times at 2-week intervals. Lung pathology, bronchoalveolar lavage fluid (BALF) cytological profiles, and inflammatory mediators in BALF were investigated. Bone marrow-derived macrophages (BMDM) from

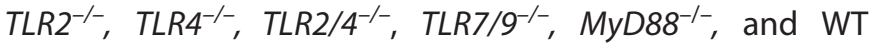
C57BL/6J mice were stimulated with $B$. adusta for $12 \mathrm{~h}$, and
}

inflammatory mediators in the culture medium were measured. Results: $B$. adusta caused lung inflammation along with Th2 cytokine [interleukin (IL)-5 and IL-13] and eosinophil-related chemokine [eotaxin and monocyte chemotactic protein (MCP-3)] production, an increase in eosinophils in $B A L F$, and eosinophil infiltration in the airways in WT and $T_{R} 4^{-/-}$mice. However, Th2 and eosinophil-related responses in $T L R 2^{-/-}$and $M y D 88^{-/-}$mice were low or undetectable. The induction of neutrophils and IL-6, IL-12, IL-17A, and MCP-1 in the BALF of MyD88 ${ }^{-/-}$mice was attenuated compared to that in WT mice. The induction of IL-6, TNF-a, MCP1 , and macrophage inflammatory protein-1 a was reduced or undetectable in B. adusta-stimulated BMDM from $T L R 7 / 9^{-/-}$ and $M y D 88^{-/-}$mice compared to WT mice. Conclusions: These results suggest that TLR2 and the adapter protein MyD88 may play an important role in the induction of eosinophils by B. adusta. However, TLR7/9-MyD88 might be important in the induction of neutrophils and the relevant inflammatory mediators, especially IL-17A.

(c) 2015 S. Karger AG, Basel

\section{KARGER 125}

(C) 2015 S. Karger AG, Basel

$1018-2438 / 15 / 1682-0096 \$ 39.50 / 0$ 


\section{Introduction}

Bjerkandera adusta is a mushroom fungus that mostly grows in fields and colonizes rotting wood [1]. Recently, direct associations between increased B. adusta exposure and allergic respiratory disease have been reported [2-4]. Ogawa et al. [5-7] encountered a cluster of patients with an intractable allergic fungal cough, which was characterized by sensitization to B. adusta; they classified it as a new type of disease known as fungus-associated cough [5-8]. Another clinical study reported a case of asthma attacks caused by inhalation of an environmental B. adust $a$ antigen in Japan [9]. Additionally, B. adusta has been reported to attach to yellow sand dust particles that reach not only East Asia but also North America and Europe via sand dust storms. Indeed, B. adusta has been frequently detected in both indoor and outdoor samples in France $[10,11]$. Therefore, $B$. adusta could have the potential to exacerbate the clinical manifestations of allergic cough, asthma, and allergic rhinitis, which are natural phenomena that influence human health globally.

In accordance with these clinical studies, our recent experimental research showed that B. adusta alone caused an eosinophil-rich pulmonary inflammatory response and Th2 cytokine [such as interleukin (IL)-5] production in mice, as well as increased inflammatory molecule secretion from bone marrow-derived macrophages (BMDM) in vitro [12]. We also found that B. adusta caused eosinophilic airway inflammation and aggravated ovalbumin-induced murine lung eosinophilia along with fibrous thickening of the subepithelial layer [13]. However, the mechanism whereby $B$. adusta induces allergic lung inflammation has not yet been adequately characterized.

The host response to invading pathogens is in part activated by a family of receptors called Toll-like receptors (TLR), which recognize conserved pathogen-associated molecular patterns that occur in microbes. Interactions between TLR and pathogen-associated molecular patterns initiate an innate immune defense against pulmonary pathogens [14]. Myeloid differentiation factor 88 (MyD88), a downstream signaling adapter molecule, is the principal adapter protein that is essential for cytokine production in response to TLR ligands.

In the present study, gene 'knockout' (TLR2 $2^{-/-}$, $T L R 4^{-/-}$, and $M y D 88^{-/-}$) and wild-type (WT) BALB/c mice were used to investigate the role of TLR and MyD88 in B. adusta-induced lung inflammation. Alveolar macrophages are key cells that provide a protective pulmonary defense against microorganisms. BMDM from
TLR2 $2^{-/-}, T L R 4^{-/-}, T L R 2 / 4^{-/-}, T L R 7 / 9^{-/-}, M y D 88^{-/-}$, and WT C57BL/6J mice were exposed to B. adusta. The induction levels of proinflammatory mediators in the culture medium were compared to investigate the role of the TLR and MyD88.

\section{Material and Methods}

Animals

Homozygous TLR2 $2^{-/-}$, TLR4 ${ }^{-/-}, M y D 88^{-/-}$, and WT mice (on a $\mathrm{BALB} / \mathrm{c}$ genetic background, $\mathrm{n}=20$ /genotype) were purchased from Oriental Bioservice (Kyoto, Japan). All animals were housed under standard conditions at the Animal Resource Center of Oita University of Nursing and Health Sciences, Japan. This study adhered to the US National Institutes of Health Guidelines for the Use of Experimental Animals.

\section{Preparation of B. adusta}

Asian sand dust bioaerosols were collected $400 \mathrm{~m}$ above the ground using a tethered balloon equipped with a bioaerosol sampler in the city of Suzu, located in the Noto Peninsula, Ishikawa Prefecture, Japan, on May 7, 2008. Bioaerosol samples were inoculated onto 4 culture agar plates, including nutrient agar, blood agar, potato dextrose agar, and Sabouraud dextrose agar. After 3 days of incubation, several microbial colonies on the agar plates were transferred to fresh agar plates. A total of 8 isolates were obtained. Full sequences of $18 \mathrm{~S}$ rRNA genes $(\sim 1,650 \mathrm{bp})$ and internal transcribed spacer regions ( $\sim 620 \mathrm{bp}$ ) of the fungal isolates were determined and compared with known sequences from the DNA Data Bank of Japan. The isolate sequences were most closely related to B. adusta (similarity $>99.9 \%$ ). The fungal isolate was also confirmed to be B. adusta by microscopy [15].

After incubation of B. adusta in liquid Trypticase Peptone medium for 3 days, $1 \mathrm{ml}$ of culture was fixed with paraformaldehyde at a final concentration of $1 \%$. Samples were stained with $4,6-\mathrm{di}$ amidino-2-phenylindole (DAPI) at a final concentration of 0.5 $\mathrm{mg} / \mathrm{ml}$ for $15 \mathrm{~min}$ and filtered through a polycarbonate filter $(0.22$ $\mathrm{mm}$ pore size; Whatman) stained with Sudan Black. After placing the filter on a slide on a drop of low-fluorescence immersion oil, a second drop of oil was added and the coverslip was placed on top. The prepared slides were observed under an epifluorescence microscope (Olympus, Tokyo, Japan) equipped with a UV excitation system. DAPI-stained cells of $B$. adusta were observed as rods ranging from 2 to $3 \mathrm{~mm}$ in width, with some cells indicating a yellow fluorescence (fig. 1).

The density range of the asexual spores ( $4-5 \mu \mathrm{m}$ in size) in the atmosphere of Suzu City during a dust storm event (May 1-3, 2011) was approximately 1-6 million particles $/ \mathrm{m}^{3}$, which is remarkably higher than normal levels $\left(\sim 5,000\right.$ particles $\left./ \mathrm{m}^{3}\right)$ [16]. It is possible that the asexual spores have adverse effects on health. Because B. adusta produces asexual spores from the hyphae, fungal hyphae were used in this study. The cultivated fungal hyphae were inactivated with $1 \%$ formalin for 1 day at $4{ }^{\circ} \mathrm{C}$ according to the vaccine manufacturer's method with slight modifications. The B. adusta that was obtained was inactivated with $1 \%$ formalin for 1 day at $4^{\circ} \mathrm{C}$, followed by centrifugation at $1,200 \mathrm{rpm}$ for $10 \mathrm{~min}$; the resulting pellet was suspended in a normal saline solution (Otsuka Co., Kyoto, Japan) [17]. The suspension was sonicated for 
1 min with a UD-201 ultrasonic disrupter with a micro-tip (Tomy, Tokyo, Japan) under cooling conditions and then it was centrifuged at 12,000 rpm for $10 \mathrm{~min}$. This operation was repeated 5 times. After the final centrifugation step, the supernatant was removed and the residual material was dried under a reduced pressure.

Analysis of Lipopolysaccharide and $\beta$-Glucan in B. adusta

Analysis of lipopolysaccharide (LPS) and $\beta$-glucan in B. adusta was conducted using a previously reported method [13]. The contents of LPS and $\beta$-glucan in B. adusta were measured via a kinetic assay using an Endospec ES-24S set (Seikagaku Corp., Tokyo, Japan) for LPS activity and a Glucatell Kit (Associates of Cape Cod Inc., East Falmouth, Mass., USA) for $\beta$-glucan activity. The experiments were performed according to the manuals provided by the manufacturers. Briefly, approximately $10 \mu \mathrm{g}$ of B. adusta (dry weight) were suspended in $1 \mathrm{ml}$ of water (LPS and $\beta$-glucan free; Seikagaku) and then allowed to stand at room temperature for $2 \mathrm{~h}$. The LPS and $\beta$-glucan concentrations in the supernatants were determined using a Pyro Color-MP:Chromogenic Diazo-Coupling Kit (Associates of Cape Cod). The detection limits for LPS and $\beta$-glucan were $0.001 \mathrm{EU} / \mathrm{ml}$ and $2 \mathrm{pg} / \mathrm{ml}$, respectively.

\section{Study Protocol}

TLR2 $2^{-/-}, \mathrm{TLR}^{-/-}, \mathrm{MyD} 88^{-/-}$, and WT mice were intratracheally instilled with normal saline (Otsuka) (control, $\mathrm{n}=10$ /genotype) or $B$. adusta $(0.8 \mu \mathrm{g} /$ mouse, $\mathrm{n}=10$ /genotype) through a polyethylene tube under anesthesia with $4 \%$ halothane (Takeda Chemical, Osaka, Japan) 4 times at 2-week intervals. Then, $24 \mathrm{~h}$ after the final intratracheal administration, mice from all groups were euthanized by exsanguination under deep anesthesia via intraperitoneal injection of pentobarbital.

\section{Bronchoalveolar Lavage}

Six of the 10 mice from each group were used for bronchoalveolar lavage fluid (BALF) and cell counts. In brief, tracheas were cannulated after the collection of blood. Lungs were lavaged with 2 injections of $0.8 \mathrm{ml}$ sterile saline at $37^{\circ} \mathrm{C}$ using a syringe. The lavaged fluid was harvested by gentle aspiration and the mean volume retrieved was $90 \%$ of the amount instilled $(1.6 \mathrm{ml})$. Fluids from the 2 lavages were pooled, cooled to $4^{\circ} \mathrm{C}$, and centrifuged at $1,500 \mathrm{rpm}$ for $10 \mathrm{~min}$. The total lavage collected from individual mice was used to measure the protein levels of cytokines and chemokines in the BALF. The total cell count of each fresh fluid specimen was determined using a hemocytometer. Differential cell counts were assessed on cytological preparations. Slides were prepared by Cytospin (Sakura Co., Ltd., Tokyo, Japan) and stained with Diff-Quik (International Reagents Co., Kobe, Japan). A total of 300 cells were counted under oil immersion microscopy [1820].

\section{Pathological Evaluation}

The remaining 4 mice were used for pathological examination. Lungs were fixed in $10 \%$ neutral phosphate-buffered formalin. After separation of the lobes, 2-mm-thick blocks were used for paraffin embedding. The embedded blocks were sectioned to a thickness of $3 \mu \mathrm{m}$ and stained with hematoxylin and eosin (HE) to evaluate the degree of eosinophil or lymphocyte infiltration in the airways, as measured from the proximal to the distal airway. Sections were also stained with periodic acid-Schiff (PAS) to evaluate

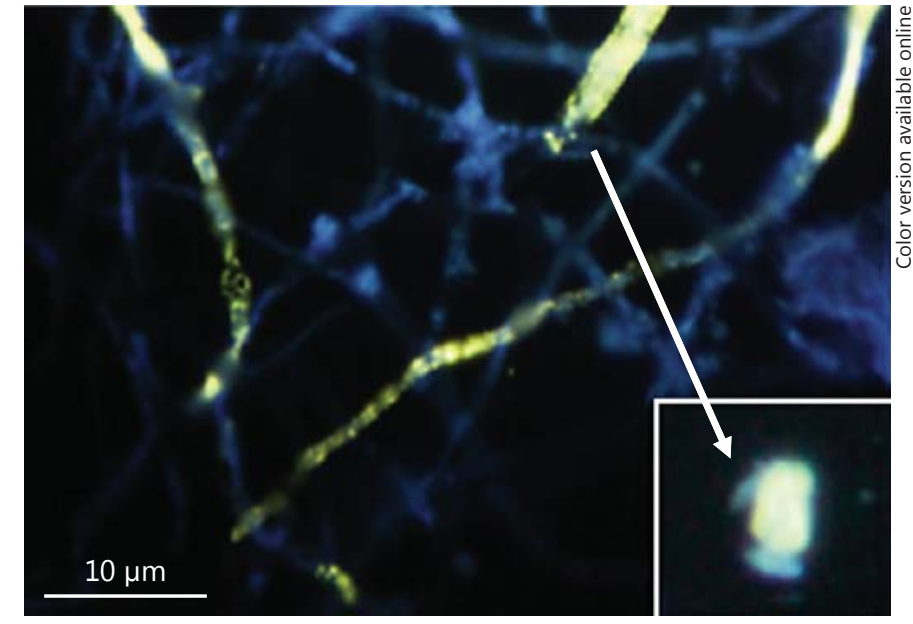

Fig. 1. Fluorescent images of B. adusta stained with DAPI. DAPIstained cells of $B$. adusta were observed as rods ranging from 2 to $3 \mathrm{~mm}$ in width, and some cells displayed a yellow fluorescence. The yellow-fluorescence filaments of B. adusta are fragmented as asexual spores (inset).

the degree of goblet cell proliferation in the bronchial epithelium. A pathological analysis of inflammatory cells and epithelial cells in the airways was performed using a Nikon ECLIPSE light microscope (Nikon Co., Tokyo, Japan) [18-20]. The degree of infiltration of neutrophils, eosinophils, and lymphocytes in the airways or proliferation of goblet cells in the bronchial epithelium was graded in a blinded fashion as follows: 0 , not present; 1 , slight; 2 , mild; 3 , moderate; 4 , moderate to marked, and 5, marked. 'Slight' was defined as less than $20 \%$ of the airway exhibiting an eosinophilic inflammatory reaction or goblet cells stained with PAS, 'mild' as $21-$ $40 \%$, 'moderate' as $41-60 \%$, 'moderate to marked' as $61-80 \%$, and marked as more than $80 \%$ [18-21]. The degree of thickening of the subepithelial layer in the main bronchus was graded on the following scale: 0 , not present; 1 , slight; 2 , mild; 3 , moderate; 4 , moderate to marked, and 5 , marked. 'Slight' was defined as $5-12 \mu \mathrm{m}$ of the main bronchus with fibroblasts stained with PAS; 'mild' as 13-20 $\mu \mathrm{m}$; 'moderate' as $21-28 \mu \mathrm{m}$; 'moderate to marked' as $29-36 \mu \mathrm{m}$, and 'marked' as more than $37 \mu \mathrm{m}[12,13]$.

Isolation and Culture of Murine BMDM

WT, TLR2 $2^{-/-}$TLR4 $4^{-/-}, T L R 2 / 4^{-/-}, T L R 7 / 9^{-/-}$, and $M y D 88^{-/-}$ mice (on a C57BL/6J background, $\mathrm{n}=4$ /genotype) were purchased from Oriental Bioservice [12]. Femurs were removed at 8 weeks of age, and soft tissue was removed and flushed with Hanks' solution to recover the bone marrow. BMDM were cultured on plastic dishes in RPMI (Nissui, Tokyo, Japan) containing penicillin-streptomycin (Gibco, New York, N.Y., USA) and 10\% inactivated fetal bovine serum (Thermo Scientific, South Logan, Utah, USA). Additionally, $10 \mathrm{ng} / \mathrm{ml}$ of granulocyte-macrophage colony-stimulating factor (PeproTech EC, London, UK) was added to the cultures on days 0 and 3. After 6 days in culture, adherent BMDM were collected via addition of $5 \mathrm{ml}$ of $0.02 \%$ EDTA, after which the loose cells were scraped off the plates. BMDM were replated at a concentration of $3 \times 10^{5}$ cells $/ \mathrm{ml}$ into 24 -well plates at $1 \mathrm{ml} /$ well [20]. 


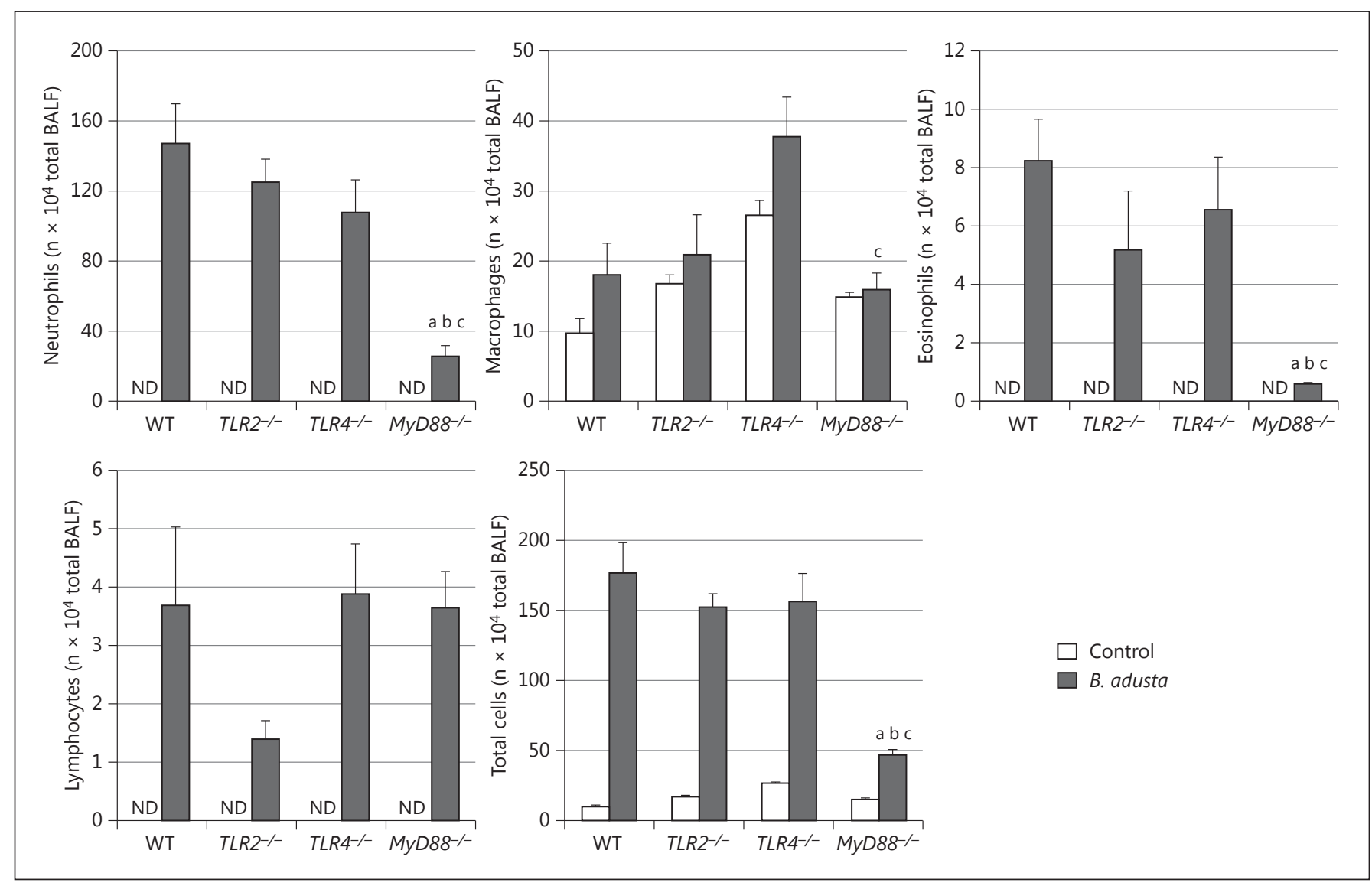

Fig. 2. Cellular profile in BALF. TLR2 $2^{-/}, T L R 4^{-/-}, M y D 88^{-/-}$, and WT mice were treated intratracheally with normal saline (control) or B. adusta ( $0.8 \mathrm{mg} /$ mouse) 4 times at 2 -week intervals. One day after the last intratracheal administration, 6 mice from each group were killed and the lavaged fluid was harvested by gentle aspiration. The total cell count of a fresh fluid specimen was determined

BMDM were incubated with PBS and B. adusta (final concentration $20 \mu \mathrm{g} / \mathrm{ml}$ ) for $12 \mathrm{~h}$. Cytokines secreted into the culture medium by BMDM were measured via enzyme-linked immunosorbent assay (ELISA).

\section{Quantitation of Cytokines}

ELISA for interleukin IL-6, IL-13, IL-17A, eotaxin, monocyte chemotactic protein (MCP)-1, and macrophage inflammatory protein (MIP)-1 $\alpha$ (R\&D Systems Inc., Minneapolis, Minn., USA), IL-5 and IL-12 (Endogen, Cambridge, Mass., USA), and MCP-3 (Bender MedSystems, Burlingame, Calif., USA) were carried out according to the manufacturer's instructions ( $\mathrm{n}=6$ per group).

\section{Statistical Analysis}

Statistical analyses of cell numbers, cytokine and chemokine protein concentrations in BALF or in supernatants of BMDM cultures, and pathological scores were conducted using Tukey's test for pairwise comparisons (KyPlot version 5; Kyens Lab Inc., Tokyo, Japan). $\mathrm{p}<0.05$ was considered statistically significant. using a hemocytometer. Differential cell counts were assessed on the slides prepared by cytospin and stained with Diff-Quik. All values are expressed as means $\pm \mathrm{SE}$. ND $=$ Not detected. ${ }^{\mathrm{a}} \mathrm{p}<0.05$ vs. WT B. adusta. ${ }^{\mathrm{b}} \mathrm{p}<0.05$ vs. TLR2 B. adusta. ${ }^{\mathrm{c}} \mathrm{p}<0.05$ vs. TLR4 B. adusta.

\section{Results}

Contents of LPS and $\beta$-Glucan in B. adusta

The $\beta$-glucan content in B. adusta was $32.8 \mu \mathrm{g} / \mathrm{mg}$. LPS was not detected in B. adusta.

\section{Inflammatory Cells in the BALF}

To evaluate the roles of TLR2, TLR4, and MyD88 in $B$. adusta-induced lung inflammation, the cellular profile of the BALF was investigated (fig. 2).

B. adusta significantly increased the number of neutrophils, eosinophils, and total cells in WT, TLR2 ${ }^{-/-}$, and $T L R 4^{-/-}$mice compared to controls $(\mathrm{p}<0.05)$; however, no increase in the number of neutrophils, eosinophils, or total cells in $M y D 88^{-/-}$mice was observed. There was no significant difference between WT and either TLR2 $2^{--}$or 

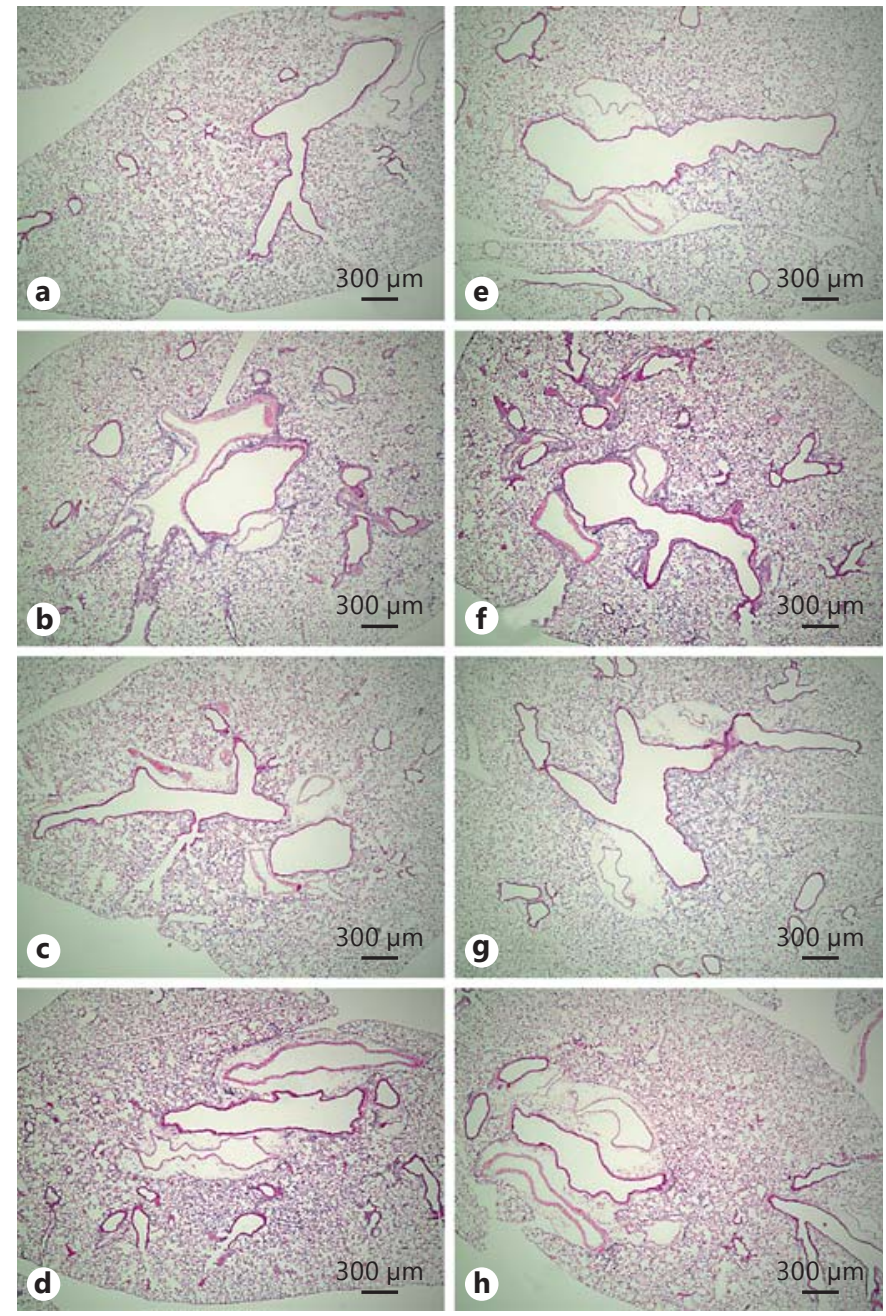

Fig. 3. Pathological changes in the lungs of mice exposed to $B$. adusta. Four mice from each group were killed for lung pathological observation and the lungs were fixed in $10 \%$ neutral phosphate-buffered formalin. The lung specimens were stained with PAS. The photograph shows a low magnification of lung tissue. a WT control. b WT B. adusta. c TLR2 $2^{-/-}$control. d TLR2 $2^{-/-}$

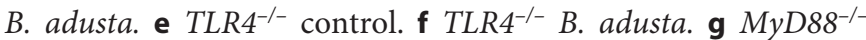
control. h $\mathrm{M} y D 88^{-/-}$B. adusta. PAS stain. There were no pathological changes in the airways exposed to saline $(\mathbf{a}, \mathbf{c}, \mathbf{e}, \mathbf{g})$. The degrees of lung inflammation and thickening of the bronchial wall in $T L R 2^{-/-}$mice were weaker than in WT or $T L R 4^{-/-}$mice $(\mathbf{b}, \mathbf{d}, \mathbf{f})$. These degrees in $M y D 88^{-/-}$mice were weaker than in TLR2 $2^{-/-}$mice (h).

$T L R 4^{-/-}$mice in terms of neutrophils or total cells in the $B$. adusta-treated group, but the eosinophil number in $T L R 2^{-/-}$mice tended to be less than that in WT or $T L R 4^{-/-}$mice. Additionally, B. adusta significantly in-
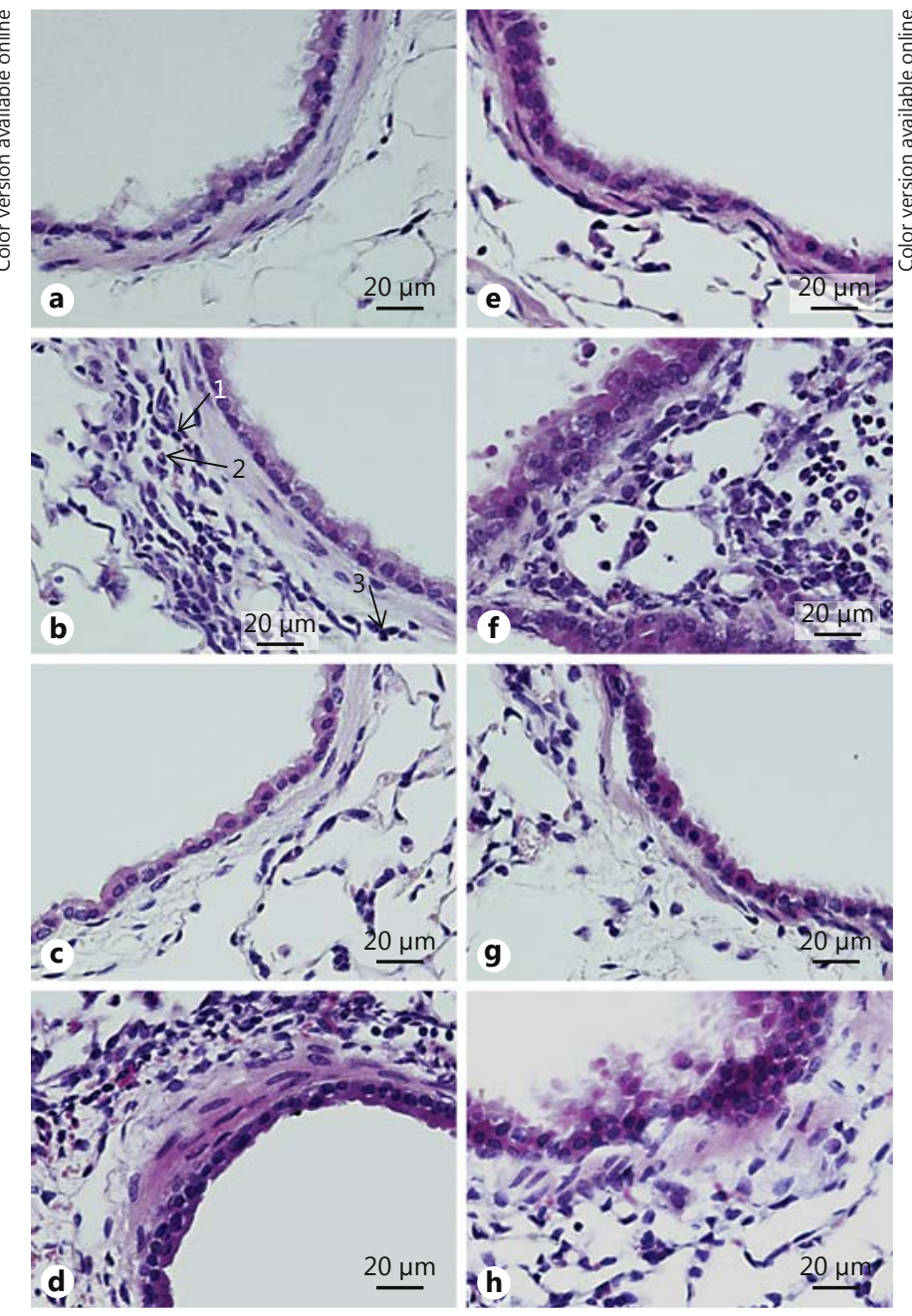

Fig. 4. Effects of B. adusta on infiltration of inflammatory cells in the airways. Four mice from each group were killed for lung pathological observation and the lungs were fixed in $10 \%$ neutral phosphate-buffered formalin. The lung specimens were stained with HE. The photograph shows a high magnification of lung tissue. a WT control. b WT B. adusta. c TLR2 $2^{-/-}$control. d TLR2 $2^{-/-} B$.

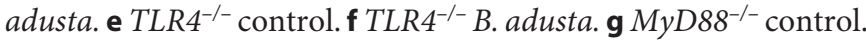
h $M y D 88^{-/-}$B. adusta. HE stain. No pathological changes were detected in the airways exposed to saline $(\mathbf{a}, \mathbf{c}, \mathbf{e}, \mathbf{g})$. Moderate infiltration of eosinophils, neutrophils, and lymphocytes in the airway submucosa of WT mice exposed to B. adusta (b). Slight to moderate infiltration of eosinophils, neutrophils, and lymphocytes in the airway submucosa of TLR $4^{-/-}$mice exposed to B. adusta (d). Very slight infiltration of neutrophils in the airway submucosa and alveoli in $M y D 88^{-/-}$mice exposed to B. adusta (h). Arrow 1, lymphocyte; arrow 2, eosinophil, and arrow 3, neutrophil.

creased the number of lymphocytes in WT and both $\mathrm{TLR}^{-/-}$and $\mathrm{MyD} 88^{-/-}$mice compared to the controls $(\mathrm{p}<0.05)$ but caused no significant increase in TLR2 $2^{-/}$ mice. 


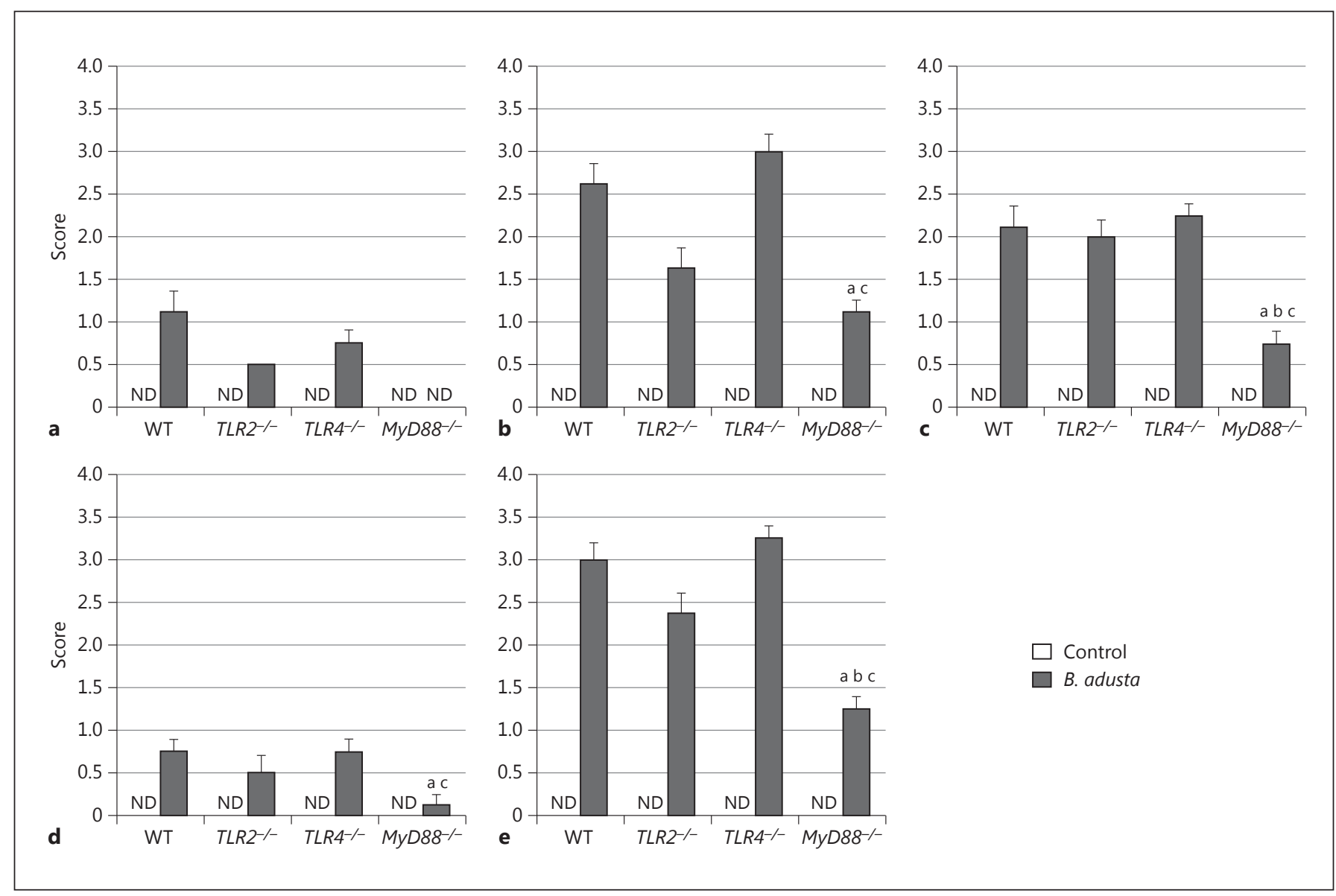

Fig. 5. Evaluation of pathological changes in the murine airway. a Proliferation of goblet cells. b Eosinophils. c Neutrophils. d Lymphocytes. e Thickening of the bronchial wall. The lung specimens were stained with PAS and HE to evaluate pathological changes. The degree of pathological changes in the airways was estimated as follows: 0 , none; 1 , slight; 2 , mild; 3 , moderate; 4 , moderate to marked, and 5, marked. All values are expressed as means $\pm \mathrm{SE}$ $(\mathrm{n}=4)$. Statistical analyses were conducted using Tukey's test for pairwise comparisons. ${ }^{\mathrm{a}} \mathrm{p}<0.05$ vs. WT B. adusta. ${ }^{\mathrm{b}} \mathrm{p}<0.05$ vs. TLR2 B. adusta. ${ }^{\mathrm{c}} \mathrm{p}<0.05$ vs. TLR4 B. adusta.

\section{Pathological Changes in the Airways}

To confirm the roles of TLR2, TLR4, and MyD88 in B. adusta-induced lung inflammation, the lung pathology of the mice was examined.

The photograph in figure 3 shows a low magnification of lung tissue. No pathological alterations were noted in the lungs of the control groups of WT, $T L R 2^{-/-}, T L R 4^{-/-}$, and $M y D 88^{-/-}$mice (fig. 3a, c, e, g). The degrees of lung inflammation and thickening of the bronchial wall in TLR2 $2^{-/}$mice exposed to B. adusta were weaker than those in WT or TLR $4^{-/-}$mice (fig. 3b, $\mathrm{d}, \mathrm{f})$. Moreover, the inflammation and bronchial wall thickening in $M y D 88^{-/-}$mice were less than in TLR2 $2^{-/-}$ mice (fig. $3 \mathrm{~h}$ ). The photograph in figure 4 shows a high magnification of lung tissue. No pathological altera- tions were noted in the lungs of the control groups of $\mathrm{WT}, T L R 2^{-/-}, T L R 4^{-/-}$, and $M y D 88^{-/-}$mice (fig. $4 \mathrm{a}, \mathrm{c}, \mathrm{e}$, g). B. adusta caused hypertrophy of airway epithelial cells, a slight proliferation of goblet cells in the airway epithelium (data not shown), and infiltration of eosinophils, neutrophils, and lymphocytes into the airway submucosa (fig. 4b, d, f).

Figure 5 shows the pathological scores. The degree of goblet cell proliferation in WT, TLR2 $2^{-/-}$, and TLR4 $4^{-/-}$ mice treated with $B$. adusta was slight, but no change was observed in $M y D 88^{-/-}$mice. The level of neutro-

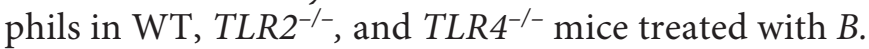
adusta was mild. The level of eosinophils in WT and $T L R 4^{-/-}$mice treated with $B$. adusta was mild to moderate, but it was slight in $T L R 2^{-/-}$and $M y D 88^{-/-}$mice. The 


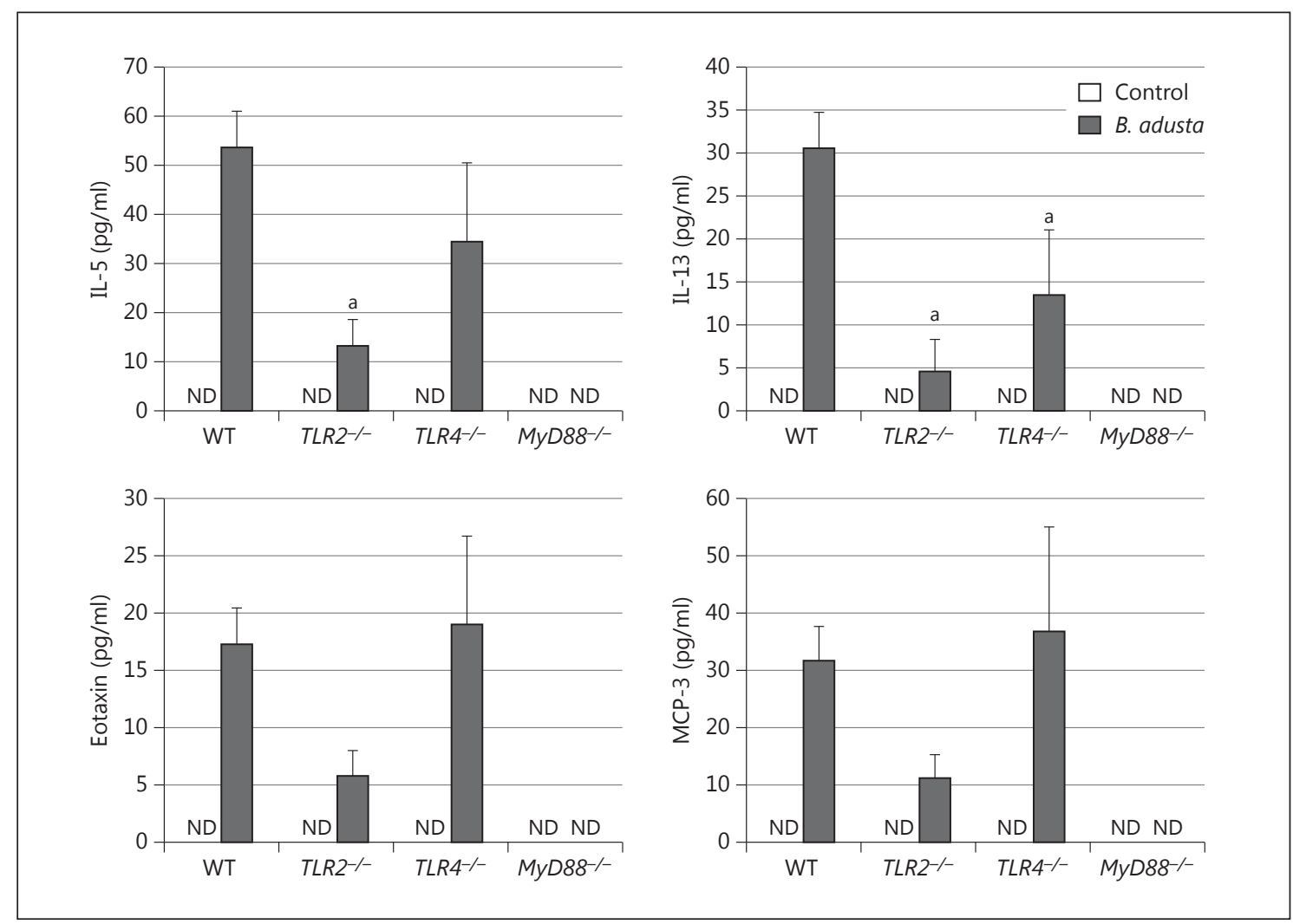

Fig. 6. Expression of IL-5, IL-13, eotaxin, and MCP-3 in BALF. TLR2 ${ }^{-/-}, T L R 4^{-/-}, M y D 88^{-/-}$, and WT mice were treated intratracheally with normal saline (control) or B. adusta ( $0.8 \mathrm{mg} / \mathrm{mouse}) 4$ times at 2-week intervals. One day after the last intratracheal administration, mice from all groups were killed and the lavaged fluid was harvested by gentle aspiration. The lavaged fluid was analyzed for IL-5, IL-13, eotaxin and MCP-3 by ELISA. All values are expressed as means $\pm \mathrm{SE} . \mathrm{ND}=$ Not detected. ${ }^{\mathrm{a}} \mathrm{p}<0.05$ vs. WT B. adusta.

level of lymphocytes in the 4 different mice was very slight. The degree of thickening of the bronchial wall in WT and TLR4 ${ }^{-/}$mice treated with B. adusta was moderate, but it was mild in TLR2 ${ }^{-/-}$mice and slight in $M y D 88^{-/-}$mice.

\section{Cytokine and Chemokine Levels in the BALF}

To investigate the roles of TLR2, TLR4, and MyD88 in B. adusta-induced lung inflammation, protein levels of cytokines and chemokines in the BALF were measured (fig. 6, 7).

B. adusta markedly increased the Th2 cytokines IL-5 and IL-13 and the eosinophil-related chemokines eotaxin and MCP-3 in WT and TLR4 ${ }^{-/-}$mice compared to the controls $(\mathrm{p}<0.05)$. However, B. adusta did not affect the expression of IL-5, IL-13, eotaxin, and MCP-3 in TLR2 $2^{-/}$ mice and did not induce detectable levels of these cytokines in $\mathrm{MyD}^{-/-}$mice.
B. adusta increased IL-17A in WT, TLR2 $2^{-/-}$, and $T L R 4^{-/-}$mice compared to the controls $(\mathrm{p}<0.05)$, but it did not induce detectable cytokine levels in $M y D 88^{-/-}$mice.

B. adusta markedly increased IL- 6 and the Th1 cytokine IL-12 in WT, TLR2 ${ }^{-/-}, T L R 4^{-/-}$, and $M y D 88^{-/-}$mice compared to the controls $(\mathrm{p}<0.05)$; the levels of IL-6 and IL-12 in $M y D 88^{-/-}$mice were lower than those in WT, $T L R 2^{-/-}$, and $T L R 4^{-/-}$mice $(\mathrm{p}<0.05)$.

\section{Cytokine and Chemokine Production in B. adusta-}

\section{Stimulated BMDM}

To characterize the role of TLR and MyD88 in the production of proinflammatory molecules induced by $B$. $a d u s t a$, in vitro assays were performed using BMDM from WT, TLR2 $2^{-/-}, T L R 4^{-/-}, T L R 2 / 4^{-/-}, T L R 7 / 9^{-/-}$, and $M y D 88^{-/-}$mice (fig. 8).

The production of IL- 6 , TNF- $\alpha$, MCP-1, and MIP- $1 \alpha$ in the culture medium of B. adusta-stimulated BMDM 


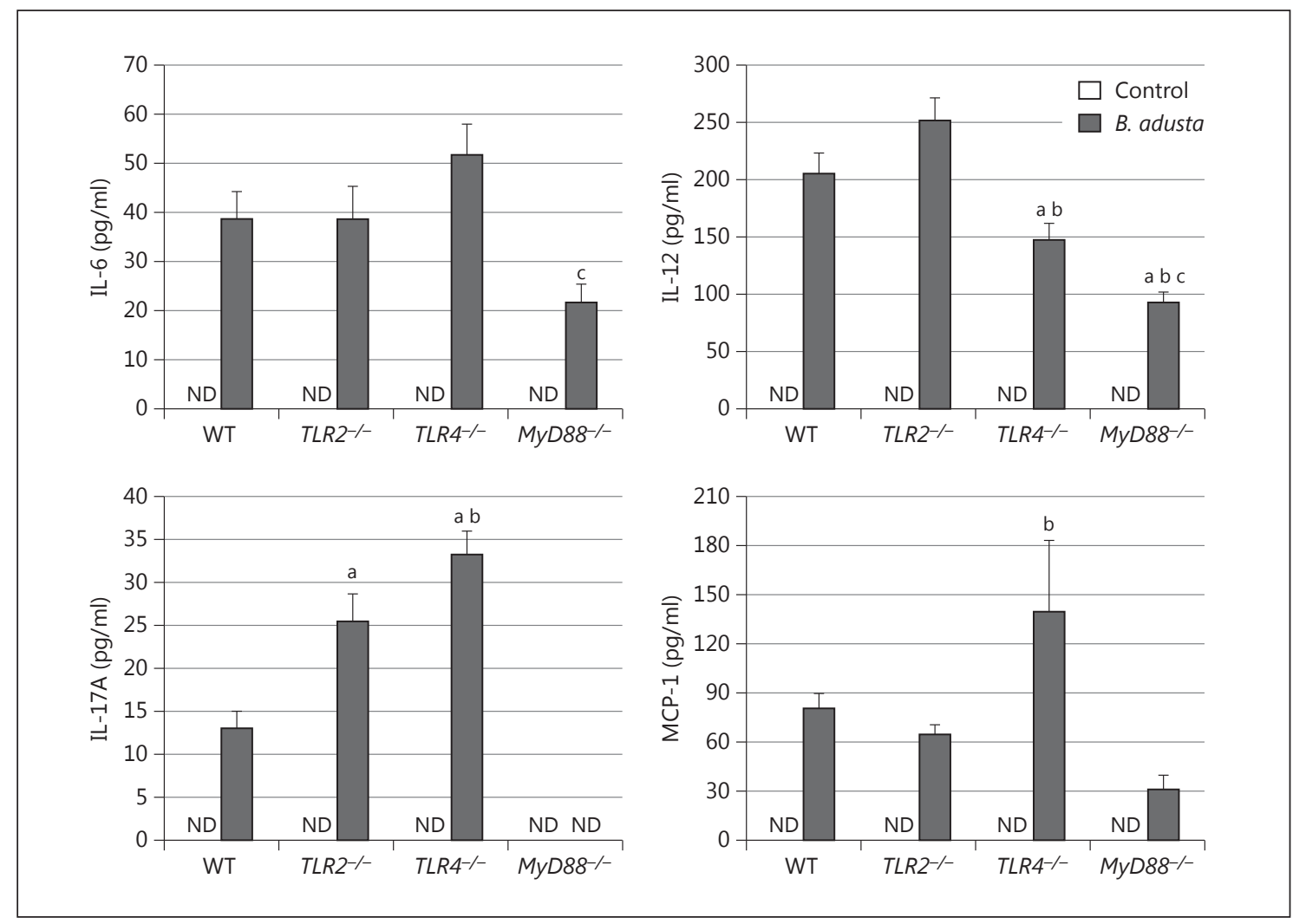

Fig. 7. Expression of IL-6, IL-12, IL-17A, and MCP-1 in BALF. TLR2-/-, TLR4 ${ }^{-/-}, M y D 88^{-/-}$, and WT mice were treated intratracheally with normal saline (control) or B. adusta ( $0.8 \mathrm{mg} / \mathrm{mouse}) 4$ times at 2-week intervals. One day after the last intratracheal administration, mice from all groups were killed and the lavaged fluid was harvested by gentle aspiration. The lavaged fluid was analyzed for IL-6, IL-12, IL-17A, and MCP-1 by ELISA. All values are expressed as means $\pm \mathrm{SE}$. ND $=$ Not detected. ${ }^{\mathrm{a}} \mathrm{p}<0.05$ vs. WT B. adusta. ${ }^{\mathrm{b}} \mathrm{p}<0.05$ vs. TLR2 B. adusta. ${ }^{\mathrm{c}} \mathrm{p}<0.05$ vs. TLR4 B. adusta.

was low or not detectable in TLR7/9 ${ }^{-/-}$and $M y D 88^{-/-}$ cells. There was no difference in the expression of these cytokines in WT, TLR2 $2^{-/-}$, TLR $4^{-/-}$, or TLR $2 / 4^{-/-}$cells, ex-

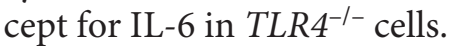

\section{Discussion}

Fungi represent the fourth leading cause of hospitalacquired infections in at-risk populations, despite the availability of efficient but costly antifungal therapies [22, 23]. Sensitization to fungi is an important factor in patients with allergic respiratory tract diseases, which play a major role in the development, persistence, and severity of lower-airway diseases, particularly asthma [24]. Recently, B. adusta has received attention because of its potential role in exacerbating the severity of allergic fungal

Lung Inflammation by $B$. adusta via TLR2/7/9-MyD88 cough, the sole presenting manifestation of bronchial asthma, caused by sensitization to this fungus [5-9].

Here, we show for the first time that B. adusta induces pulmonary inflammation via mechanisms that are dependent on TLR-MyD88 signaling. MyD88-deficient mice had a profoundly attenuated inflammatory response to B. adusta compared to WT mice, as their airway inflammatory infiltrate was virtually negligible compared to that of the latter group. TLR2-deficient mice showed attenuated B. adusta-induced eosinophils in BALF and the airways compared to WT mice. Reflecting this reduced inflammation, the amounts of Th2 cytokines and eosinophil-related proteins released into the airways, as measured in BALF, were lower in TLR2-deficient mice than in WT mice and were undetectable in $M y D 88$-deficient mice after intratracheal addition of $B$. adusta. 


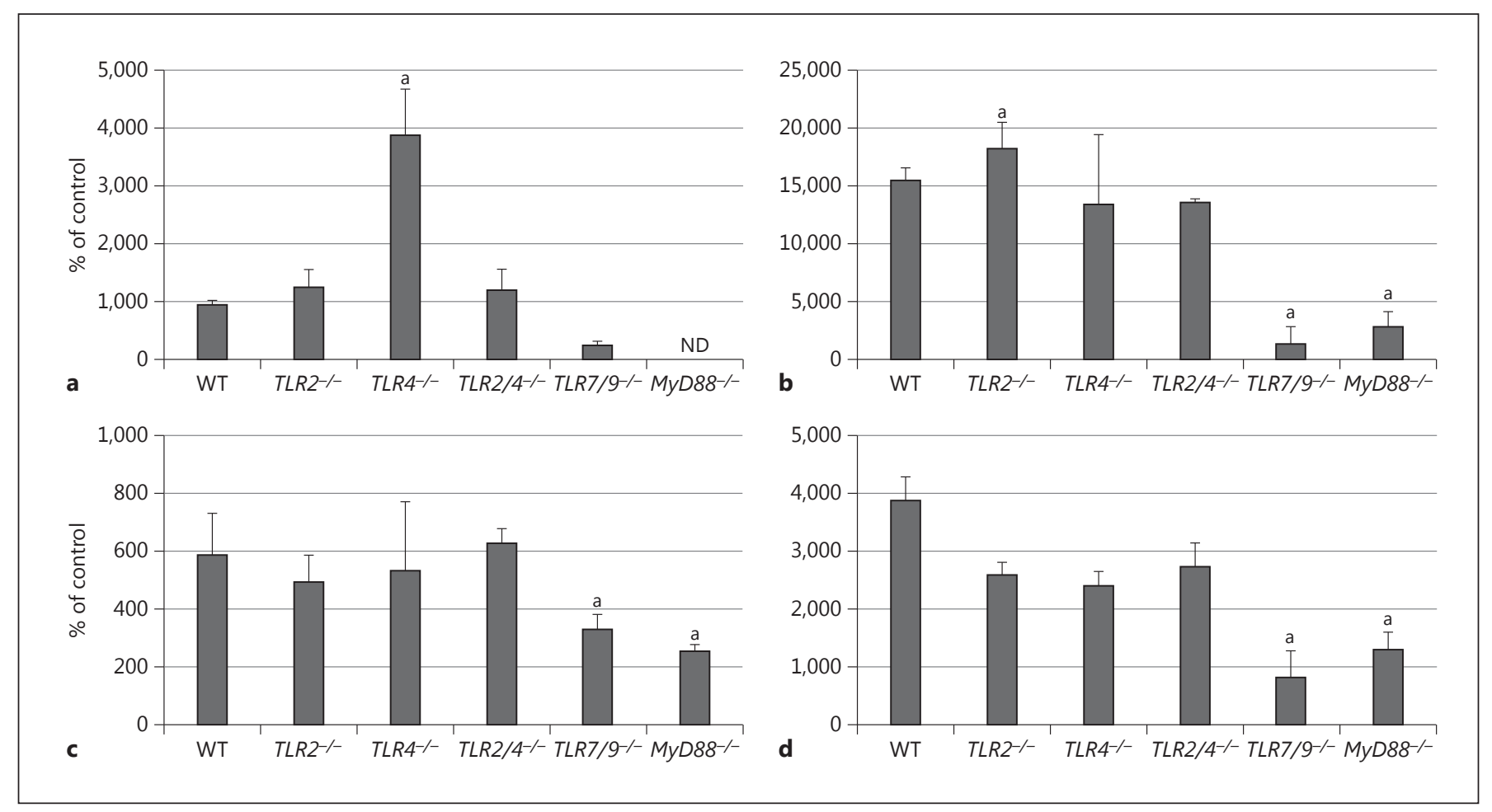

Fig. 8. Expression of cytokines and chemokines in cell culture medium by B. adusta. BMDM were plated in 24well plates at a density of $3 \times 10^{5}$ cells/well and incubated with PBS or B. adusta (final concentration $20 \mu \mathrm{g} / \mathrm{ml}$ ) for $12 \mathrm{~h}$. Supernatants were analyzed for IL-6 (a), TNF- $\alpha$ (b), MCP-1 (c), and MIP-1a (d) production by ELISA. $\mathrm{n}=4$. Data are presented as means $\pm \mathrm{SE} . \mathrm{ND}=$ Not detected. ${ }^{\mathrm{a}} \mathrm{p}<0.05 \mathrm{vs}$. WT.

Generally, fungi are protected by a cell wall, which is a highly complex and flexible meshwork of carbohydrate polymers, such as mannans, $\beta$-glucans, and chitin, that are interwoven in a protein matrix [23]. $\beta$-Glucans of several fungal species are recognized by TLR2 [25-27]. TLR2 ligands like Pam3Cys can activate a Th2 immune response and promote experimental asthma in mice [28]. Chitin is a complex adjuvant that augments Th2, Th1, humoral, and IL-17 responses, both in vivo and in vitro, mediated by pathways involving TLR2, MyD88, and IL17A [29]. In this study, B. adusta containing $\beta$-glucan and chitin may have caused eosinophil infiltration in the airways by production of Th2 cytokines via the TLR2MyD88 pathway. The eosinophils have been found to induce DC maturation through release of their granule protein eosinophil-derived neurotoxin, which can act as an agonist of TLR2 in DC [30]. These Th2 cytokines (IL5 and IL-13) and chemokines (eotaxin and MCP-3) are key mediators of the symptoms of asthma and they are critical for the recruitment and survival of eosinophils [31].
In the present study, the test sample of the fungus was not contaminated with LPS. B. adusta caused an increase in neutrophils in BALF and in the airways of WT mice. On the other hand, TLR4-deficient mice treated with $B$. adusta exhibited slightly attenuated neutrophil numbers in BALF. However, the degree of neutrophil infiltration in the airways was similar to that in WT mice exposed to B. adusta. The levels of IL-6, IL-17A, and MCP-1 in the BALF of TLR4-deficient mice were higher than those in B. adusta-treated WT mice. Therefore, we conclude that TLR4 may not contribute to B. adusta-induced neutrophil recruitment.

On the other hand, these proinflammatory mediators were greatly attenuated or not detected in $M y D 88$-deficient mice. Interestingly, in our in vitro experiments, BMDM from $T L R 7 / 9^{--}$mice, similar to those from $M y D 88^{-/-}$mice, secreted lower levels of cytokines into the culture medium compared to BMDM from $T L R 2^{-/-}$, $T L R 4^{-/-}$, and TLR $2 / 4^{-{ }^{--}}$mice. This finding suggests that both TLR7 and TLR9, as well as MyD88, are required to promote $B$. adusta-induced lung inflammation. 
Single-stranded RNA molecules from Candida spp. are ligands for TLR7 in mouse bone marrow-derived dendritic cells [32]. TLR9-mediated sensing of fungal genomic DNA appears to be conserved across fungal species [33-36], and recruitment of TLR9 to fungi-containing phagosomes has been observed in several fungal species [37]. In our in vitro study, our data suggest that $B$. adusta also induces cytokine expression in BMDM by TLR7/TLR9-MyD88 signaling. The induction of IL-17A secreted from Th17 cells contributes to neutrophil infiltration in airway inflammation in allergic asthma and might be involved in antifungal host defense responses [38]. Therefore, it is possible that for TLR7 and TLR9 the adapter protein MyD88 is important in the induction of neutrophils and the relevant inflammatory mediators, especially IL-17A.

Dectin-1 is another innate immune receptor that mediates protection from fungal infection in mice and humans. Dectin-1, expressed on the surface of antigen-presenting cells, like macrophages and dendritic cells, is a sensor of invading fungi and elicits predominantly Th17mediated immune responses [39]. Dectin-1 consists of an extracellular C-type lectin domain and an intracellular immunoreceptor tyrosine-based activation motif and responds to $\beta$ - $(1,3)$-glucan, a major cell wall component common to most fungal pathogens [40]. Recent reports have clearly implicated that dectin-1 and MyD88 collaboratively drive cellular responses to fungal $\beta$-glucans [41]. In this study, MyD88 is a key molecule in B. adusta-mediating inflammatory responses, and the induction of MyD88 might also come from another receptor dectin-1.

In summary, B. adusta induces a mixed Th2 and Th17 response and lung inflammation with eosinophils and neutrophils in mice. Recognition of B. adusta by TLR2, TLR7/9, and MyD88 has been implicated in the antifungal host defense response. If the B. adusta-induced lung inflammation causes an exacerbated allergic reaction, there is an urgent need to identify a B. adusta-specific IgE antibody in future studies. These findings will inform the treatment of $B$. adusta-induced airway inflammation in clinical settings.

\section{Acknowledgments}

This work was supported by the National Natural Science Foundation of China (No. 81302403), the Ministry of Education, Culture, Sports, Science and Technology of Japan (No. 22241011), and the Global Environment Research Fund of the Ministry of the Environment, Japan (5-1457). We appreciate the vital contributions of students at Oita University of Nursing and Health Sciences to this research.

\section{References}

1 Wang Y, Vazquez-Duhalt R, Pickard MA: Effect of growth conditions on the production of manganese peroxidase by three strains of Bjerkandera adusta. Can J Microbiol 2001;47: 277-282.

2 Ogawa H, Fujimura M, Satoh K, Makimura K: Re: Integrated research on the association between climate change and Bjerkandera allergy. J Allergy Clin Immunol Pract 2013;1:543.

3 Ogawa H, Fujimura M, Takeuchi Y, Makimura K: Possible roles of 2 basidiomycetous fungi in allergic fungal respiratory disease. J Allergy Clin Immunol 2012;130:279-280.

4 Ogawa H, Fujimura M, Takeuchi Y, Makimura K: Role of fungal colonization for sensitization in asthma. Clin Exp Allergy 2012;42: 1540-1541.

5 Ogawa H, Fujimura M, Takeuchi Y, Makimura K, Satoh K: Sensitization to Bjerkandera adusta enhances severity of cough symptom in patients with fungus-associated chronic cough (FACC). Med Mycol J 2011;52:205212.

6 Ogawa H, Fujimura M, Takeuchi Y, Makimura $\mathrm{K}$ : Is Bjerkandera adusta important to fungusassociated chronic cough as an allergen? Eight cases' reports. J Asthma 2009;46:849-855.
7 Ogawa H, Fujimura M, Takeuchi Y, Makimura K: Clinical experience with low-dose itraconazole in chronic idiopathic cough. Cough 2013;9:1.

8 Yamaura M, Satoh K, Yamazaki T, Ogawa H, Makimura K: Specific detection of Bjerkandera adusta by polymerase chain reaction and its incidence in fungus-associated chronic cough. Mycopathologia 2013;176:337-343.

9 Katayama N, Fujimura M, Yasui M, Ogawa H, Nakao S: Hypersensitivity pneumonitis and bronchial asthma attacks caused by environmental fungi. Allergol Int 2008;57:277-280.

10 Sautour M, Sixt N, Dalle F: Profiles and seasonal distribution of airborne fungi in indoor and outdoor environments at a French hospital. Sci Total Environ 2009;407:3766-3771.

11 Ogawa H, Fujimura M, Satoh K, Makimura K: Is Bjerkandera allergy affected by the arrival of yellow sand dust? Allergol Int 2013;62:517518.

12 He M, Ichinose T, Liu B, Song Y, Yoshida Y, Kobayashi F, Maki T, Yoshida S, Nishikawa M, Takano H, Sun G: Silica-carrying particulate matter enhances Bjerkandera adusta-induced murine lung eosinophilia. Environ Toxicol 2014, DOI: 10.1002/tox.22025.
13 Liu B, Ichinose T, He M, Kobayashi F, Maki T, Yoshida S, Yoshida Y, Arashidani K, Takano H, Nishikawa M, Sun G, Shibamoto T: Lung inflammation by fungus, Bjerkandera adusta isolated from Asian sand dust (ASD) aerosol and enhancement of ovalbumin-induced lung eosinophilia by ASD and the fungus in mice. Allergy Asthma Clin Immunol 2014;10:10.

14 Aryan Z, Holgate ST, Radzioch D, Rezaei N: A new era of targeting the ancient gatekeepers of the immune system: Toll-like agonists in the treatment of allergic rhinitis and asthma. Int Arch Allergy Immunol 2014;164:46-63.

15 Kobayashi F, Kodanikuchi K, Kakikawa M, Maki T, Yamada M, Tobo Y, Hong CS, Matsuki A, Iwasaka Y: Direct samplings, separated culture, and identifications of Kosa bioaerosols over Noto Peninsula, Suzu City (Japanese). Earozoru Kenkyu 2010;25:23-28.

16 Maki T, Fukushima R, Kobayashi F, Yamada M, Hasegawa H, Iwasaka Y: Analysis of airborne-bacterial compositions using $16 \mathrm{~S}$ rDNA clone library technique (in Japanese). Bunseki Kagaku 2013;62:1095-1104. 
17 Holtfreter S, Jursa-Kulesza J, Masiuk H, Verkaik NJ, de Vogel C, Kolata J, Nowosiad M, Steil L, van Wamel W, van Belkum A, Völker U, Giedrys-Kalemba S, Bröker BM: Antibody responses in furunculosis patients vaccinated with autologous formalin-killed Staphylococcus aureus. Eur J Clin Microbiol Infect Dis 2011;30:707-717.

18 Ichinose T, Yoshida S, Hiyoshi K, Sadakane K, Takano H, Nishikawa M, Mori I, Yanagisawa R, Kawazato H, Yasuda A, Shibamoto T: The effects of microbial materials adhered to Asian sand dust on allergic lung inflammation. Arch Environ Contam Toxicol 2008;55: 348-357.

19 He M, Ichinose T, Yoshida S, Nishikawa M, Mori I, Yanagisawa R, Takano H, Inoue $\mathrm{K}$, Sun G, Shibamoto T: Airborne Asian sand dust enhances murine lung eosinophilia. Inhal Toxicol 2010;22:1012-1025.

20 He M, Ichinose T, Song Y, Yoshida Y, Arashidani K, Yoshida S, Liu B, Nishikawa M, Takano H, Sun G: Effects of two Asian sand dusts transported from the dust source regions of Inner Mongolia and Northeast China on murine lung eosinophilia. Toxicol Appl Pharmacol 2013;272:647-655.

21 Ren Y, Ichinose T, He M, Song Y, Yoshida Y, Yoshida S, Nishikawa M, Takano H, Sun G, Shibamoto T: Enhancement of OVA-induced murine lung eosinophilia by co-exposure to contamination levels of LPS in Asian sand dust and heated dust. Allergy Asthma Clin Immunol 2014;10:30.

22 Knutsen AP, Bush RK, Demain JG, Denning DW, Dixit A, Fairs A, Greenberger PA, Kariuki B, Kita H, Kurup VP, Moss RB, Niven RM, Pashley CH, Slavin RG, Vijay HM, Wardlaw AJ: Fungi and allergic lower respiratory tract diseases. J Allergy Clin Immunol 2012;129: 280-291.

23 Gow NA, Hube B: Importance of the Candida albicans cell wall during commensalism and infection. Curr Opin Microbiol 2012;15:406412.

24 Levitz SM: Innate recognition of fungal cell walls. PLoS Pathog 2010;6:e1000758.
25 Viriyakosol S, Fierer J, Brown GD, Kirkland TN: Innate immunity to the pathogenic fungus Coccidioides posadasii is dependent on Toll-like receptor 2 and Dectin-1. Infect Immun 2005;73:1553-1560.

26 Netea MG, Ferwerda G, van der Graaf CA Van der Meer JW, Kullberg BJ: Recognition of fungal pathogens by Toll-like receptors. Curr Pharm Des 2006;12:4195-4201.

27 Sorgi CA, Secatto A, Fontanari C, Turato WM, Belangér C, de Medeiros AI, Kashima S, Marleau S, Covas DT, Bozza PT, Faccioli LH: Histoplasma capsulatum cell wall \{beta\}-glucan induces lipid body formation through CD18, TLR2, and dectin-1 receptors: correlation with leukotriene B4 generation and role in HIV-1 infection. J Immunol 2009;182: 4025-4035.

28 Redecke V, Häcker H, Datta SK, Fermin A, Pitha PM, Broide DH, Raz E: Cutting edge: activation of Toll-like receptor 2 induces a Th2 immune response and promotes experimental asthma. J Immunol 2004;172:27392743.

29 Da Silva CA, Pochard P, Lee CG, Elias JA: Chitin particles are multifaceted immune adjuvants. Am J Respir Crit Care Med 2010;182: 1482-1491.

30 Yang D, Chen Q, Su SB, Zhang P, Kurosaka $\mathrm{K}$, Caspi RR, et al: Eosinophil-derived neurotoxin acts as an alarmin to activate the TLR2 MyD88 signal pathway in dendritic cells and enhances Th2 immune responses. J Exp Med 2008;205:79-90.

31 Foster PS, Hogan SP, Ramsay AJ, Matthaei KI, Young IG: Interleukin 5 deficiency abolishes eosinophilia, airway hyperreactivity, and lung damage in a mouse asthma model. J Exp Med 1996;183:195-201.

32 Romani L: Immunity to fungal infections. Nat Rev Immunol 2011;11:275-288.

33 Biondo C, Signorino G, Costa A, Midiri A, Gerace E, Galbo R, Bellantoni A, Malara A, Beninati C, Teti G, Mancuso G: Recognition of yeast nucleic acids triggers a host-protective type I interferon response. Eur J Immunol 2011;41:1969-1979.

34 Nakamura K, Miyazato A, Xiao G, Hatta M, Inden K, Aoyagi T, Shiratori K, Takeda $\mathrm{K}$, Akira S, Saijo S, Iwakura Y, Adachi Y, Ohno N, Suzuki K, Fujita J, Kaku M, Kawakami K: Deoxynucleic acids from Cryptococcus neoformans activate myeloid dendritic cells via a TLR9-dependent pathway. J Immunol 2008; 180:4067-4074.
35 Miyazato A, Nakamura K, Yamamoto N, Mora-Montes HM, Tanaka M, Abe Y, Tanno D, Inden $\mathrm{K}$, Gang X, Ishii K, Takeda K, Akira S, Saijo S, Iwakura Y, Adachi Y, Ohno N, Mitsutake K, Gow NA, Kaku M, Kawakami K Toll-like receptor 9-dependent activation of myeloid dendritic cells by deoxynucleic acids from Candida albicans. Infect Immun 2009; 77:3056-3064.

36 Ramirez-Ortiz ZG, Specht CA, Wang JP, Lee CK, Bartholomeu DC, Gazzinelli RT, Levitz SM: Toll-like receptor 9-dependent immune activation by unmethylated $\mathrm{CpG}$ motifs in $A s$ pergillus fumigatus DNA. Infect Immun 2008; 76:2123-2129.

37 Kasperkovitz PV, Cardenas ML, Vyas JM: TLR9 is actively recruited to Aspergillus fumigatus phagosomes and requires the $\mathrm{N}$-terminal proteolytic cleavage domain for proper intracellular trafficking. J Immunol 2010;185: 7614-7622.

38 Naji N, Smith SG, Gauvreau GM, O’Byrne PM: T helper 17 cells and related cytokines after allergen inhalation challenge in allergic asthmatics. Int Arch Allergy Immunol 2014 165:27-34

39 Trinath J, Holla S, Mahadik K, Prakhar P, Singh V, Balaji KN: The WNT signaling pathway contributes to dectin-1-dependent inhibition of Toll-like receptor-induced inflammatory signature. Mol Cell Biol 2014;34: 4301-4314.

40 Rivera A, Hohl TM, Collins N, Leiner I, Gallegos A, Saijo S, Coward JW, Iwakura Y, Pamer EG: Dectin-1 diversifies Aspergillus fumigatus-specific $\mathrm{T}$ cell responses by inhibiting T helper type $1 \mathrm{CD} 4 \mathrm{~T}$ cell differentiation. J Exp Med 2011;208:369-381.

41 Cohen NR, Tatituri RV, Rivera A, Watts GF Kim EY, Chiba A, Fuchs BB, Mylonakis E, Besra GS, Levitz SM, Brigl M, Brenner MB Innate recognition of cell wall $\beta$-glucans drives invariant natural killer $\mathrm{T}$ cell responses against fungi. Cell Host Microbe 2011;10: 437-450. 